\title{
Osteoporosis in the lower extremities in chronic spinal cord injury
}

\author{
Angela Frotzler ${ }^{1} \cdot$ Jörg Krebs ${ }^{1} \cdot$ Andrea Göhring $^{2} \cdot$ Kathrin Hartmann $^{3} \cdot$ Stefanie Tesini $^{1} \cdot$ Kurt Lippuner $^{4}$
}

Received: 2 July 2019 / Revised: 30 October 2019 / Accepted: 30 October 2019 / Published online: 15 November 2019

(c) The Author(s), under exclusive licence to International Spinal Cord Society 2019

\begin{abstract}
Study design Cross-sectional study.

Objectives To investigate the effect of chronic motor complete spinal cord injury (SCI) and sex on bone densitometry parameters of the hip, femoral neck, tibial epiphysis, and diaphysis and on long bone fractures.

Setting SCI rehabilitation center.

Methods Women and men with long-term ( $\geq 7$ years) motor complete SCI were compared with able-bodied women and men. Dual-energy X-ray absorptiometry was used to assess bone densitometry parameters at the hip and femoral neck, whereas peripheral quantitative computed tomography was used for the tibial epiphysis and diaphysis.

Results The data of 18 women and 25 men with SCI with a mean age of $54.7 \pm 12.4$ and $53.5 \pm 8.6$ years, respectively, were analyzed. As reference groups, 74 able-bodied women and 46 men with a mean age of $51.0 \pm 13.1$ and $50.9 \pm 11.2$ years were evaluated. Most bone densitometry values were significantly $(p \leq 0.033)$ lower in the SCI compared with the reference groups, including total bone mineral density at the distal tibial epiphysis (-58.0\% in SCI women and $-53.6 \%$ in SCI men). Fracture rates per 100 patient-years were 3.17 and 2.66 in women and men with SCI compared with 0.85 and 0.21 in ablebodied women and men, respectively.

Conclusions Compared with able-bodied women and men, individuals with chronic motor complete SCI showed considerably lower bone densitometry values and a higher historical fracture rate. These findings support the need for preventative and therapeutic strategies against bone loss in individuals with SCI.
\end{abstract}

\section{Introduction}

Bone loss is a common secondary condition of spinal cord injury (SCI) and affects mainly the paralyzed extremities [1-3]. The rate of bone loss is greatest during the first year after SCI, with a reduction in proximal femoral bone mineral density (BMD) of $3.0 \%$ per month [4]. This reduction in proximal femoral BMD is accompanied by a three times greater reduction in bone strength [5]. Within

These authors contributed equally and should be considered co-first authors: Angela Frotzler, Jörg Krebs

Angela Frotzler

angela.frotzler@paraplegie.ch

1 Clinical Trial Unit, Swiss Paraplegic Centre, Nottwil, Switzerland

2 Paraplegiology, Swiss Paraplegic Centre, Nottwil, Switzerland

3 Sports Therapy, Swiss Paraplegic Centre, Nottwil, Switzerland

4 Department of Osteoporosis, Inselspital, Bern University Hospital, University of Bern, Bern, Switzerland the first 7 years after motor complete SCI, BMD in the lower extremities (femoral neck and diaphysis, proximal tibia) decreases by $50-70 \%$ [1,6] and seems to stabilize thereafter [7]. The bone loss rate in the lower extremities after SCI shows large inter-individual differences, ranging from 8 to $83 \%$ in tibial trabecular bone within the first 3 years after SCI [3].

The clinical relevance of the extensive loss of bone mass in the paralyzed extremities lies in the increased fracture risk. Zehnder et al. [8] reported an overall fracture incidence of $2.2 \%$ per year with a mean duration of 8.9 years until the first fracture after motor complete SCI. Long bone fractures after SCI often occur as a result of a minor trauma, such as falling out of a wheelchair.

The majority of previous studies has focused on bone loss and fracture occurrence in men with SCI [3, 6, 8-11] or on bone loss within the first years after SCI, i.e., the rapid resorption phase [1,3]. There are only sparse reports regarding changes in bone quantity and quality in women with SCI, and they are based on small sample sizes [12]. Some authors have reported lower BMD and bone mineral content (BMC) values in women with SCI compared with 
men with SCI [12]. Others, such as Copaud et al. [11], observed no significant effect of sex on BMD or BMC.

There is a lack of data concerning the long-term course of bone quality and fracture occurrence after SCI. We have therefore investigated the extent of bone loss at fracture prone sites as well as the fracture occurrence in women and men with long-term ( $\geq 7$ years post injury) motor complete SCI.

\section{Methods}

\section{Participants}

This cross-sectional study was conducted at a single SCI rehabilitation center. In- and out-patients who met the following criteria were eligible for inclusion: traumatic, motor complete SCI (American Spinal Injury Association Impairment Scale (AIS) A \& B), 7 years or more post injury and onset of SCI at a minimum age of 18 years. The time period ( $\geq 7$ years) after SCI was chosen to ensure that the initial and most pronounced bone loss had already occurred and that bone loss had stabilized at a lower rate $[6,7]$. The following data were collected: age, sex, and years post injury, AIS, lesion level, intake of bone-active drugs, intake of calcium or vitamin $\mathrm{D}$ and the number of long bone fractures after SCI. The SCI lesion level was classified as cervical, thoracic or lumbar.

Data were also collected for a convenience reference sample of 174 women and 86 men without SCI and older than 18 years but younger than 75 years.

\section{Bone measurements}

Bone scans of the total hip and femoral neck were taken with a densitometer (Hologic, Inc., Waltham, MA, USA) using dual-energy X-ray absorptiometry (DXA) according to the International Society of Clinical Densitometry guidelines. Assessments with DXA result in a twodimensional projection of the bone and therefore BMD is expressed as mass per area $\left(\mathrm{g} / \mathrm{cm}^{2}\right)(\mathrm{aBMD})$. Hip scans were performed at the nondominant leg. If a hip joint endoprosthesis or severe hip contractures were present, the contralateral site was assessed. The $Z$ - and $T$-score were determined to classify individuals with regard to their bone status as either normal ( $T$-score $>-1)$, osteopenic ( $T$-score from -1 to -2.5$)$ or osteoporotic $(T$-score $\leq-2.5)$ based on the lowest value of the total hip or femoral neck.

Peripheral quantitative computed tomography (pQCT) (XCT 3000, Stratec Medizintechnik, Germany) was used to assess volumetric bone parameters at the tibia of the nondominant leg. The BMD results were therefore reported as mass per volume $\left(\mathrm{mg} / \mathrm{cm}^{3}\right)$ (vBMD). Bone scans were performed at 4 and $38 \%$ of the total tibia length, starting at the distal endplate of the tibia, in order to measure the trabecular and cortical bone compartments separately. At the epiphysis (i.e., $4 \%$ scan site), total bone cross-sectional area (CSA), BMC, total vBMD (vBMDtot), and trabecular vBMD (vBMDtrab) were measured. At the bone diaphysis (i.e., 38\% scan site), total bone CSA (CSAtot), cortical bone CSA (CSAcort), cortical thickness, cortical vBMD (vBMDcort), BMC, and polar strength-strain index (SSIpol) were determined.

Densitometers for DXA and peripheral QCT measurements were both calibrated daily with a phantom according to the manufacturer's recommendations.

\section{Analyses}

The Kolmogorov-Smirnov and Shapiro-Wilks tests were used to assess if the data were normally distributed. Descriptive statistics were used to present the data as frequencies or mean and standard deviation (SD) or 95\% confidence interval (CI) where appropriate.

Not all individuals of the reference group were included in the analyses. Propensity score matching was used to balance the age between the individuals with SCI and the individuals in the reference groups. The propensity score was calculated using a logistic regression model. Each individual with SCI was matched to five reference individuals (with replacement: an individual may be drawn more than once). Only these were included in the analyses. The SCI duration of an individual was used to determine the relevant time period for the evaluation of long bone fractures in the five matched individuals. The Kaplan-Meier one-minus-survival analysis was used to graphically present the probability estimates for the occurrence of the first fracture.

The effects of SCI on bone densitometry parameters were investigated for women and men separately using a weighted (according to number of replacements) analysis of covariance (ANCOVA) (covariate: age). Differences in all other numeric data between individuals with SCI and the reference group as well as between sexes were investigated using the independent $t$-test. The Chi-square test (or exact Fisher's test where appropriate) was used to test for differences regarding ordinal and nominal data between individuals with SCI and the reference group as well as between sexes. The level of significance was set at $\alpha=0.05$. Statistical analyses were performed using the SPSS software (Version 25, IBM, Somers, NY, USA).

\section{Results}

A total of 18 women with SCI and 25 men with SCI with a mean $( \pm \mathrm{SD})$ age of $54.7 \pm 12.4$ and $53.5 \pm 9.4$ years $(p=$ 
0.73), respectively, were included. From the reference group, 74 women without SCI aged $51.0 \pm 13.1$ years and 46 men without SCI aged $50.9 \pm 11.2$ years were selected for analysis using propensity score matching. There were no significant age differences between women with SCI $(p=$ $0.24)$ or men with SCI $(p=0.27)$ and their respective reference group. For women and men with SCI, the age at SCI was $31.9 \pm 11.6$ and $26.3 \pm 5.1$ years $(p=0.07)$, respectively, and the duration of SCI was $23.3 \pm 9.7$ and $26.3 \pm 9.3$ years $(p=0.15)$, respectively. There were no significant differences between women and men with SCI in the proportions of individuals with tetraplegia (7/18 vs. $7 / 25)(p=0.45)$ and individuals with flaccid SCI (1/18 vs. $2 / 25)(p=0.76)$.

\section{Comparisons with reference group}

In comparison with their reference group, women with SCI showed significantly $(p<0.001)$ and markedly reduced bone density values in the femur (i.e., total hip, femoral neck) and tibia (i.e., distal epiphysis, diaphysis) (Fig. 1), with the exception of CSAtot in the distal tibial epiphysis (Table 1).

Likewise, the bone values of men with SCI were significantly $(p \leq 0.002)$ and markedly reduced in the femur (i.e., total hip, femoral neck) and tibia (i.e., distal epiphysis, diaphysis) (Fig. 2), compared with the reference group, with the exception of CSAtot in the distal tibia (Table 2).

Both women and men with SCI demonstrated a similar extent of bone loss in the femur (i.e., total hip, femoral neck) and tibia (i.e., distal epiphysis, diaphysis) in comparison with the respective reference group (Table 1 and 2). The difference in vBMDtrab of the distal tibia was most prominent.

\section{Comparisons between sexes}

In the individuals with SCI, the total hip and femoral neck $Z$-scores were lower in women compared with men $(-0.32$, $95 \% \mathrm{CI}-0.91$ to 0.28 and $-0.28,95 \% \mathrm{CI}-0.94$ to 0.37 ), but the differences did not reach statistical significance (total hip $p=0.29$ and femoral neck $p=0.38$ ).

Osteoporosis was significantly $(p<0.0001)$ more prevalent in women with SCI $(72.2 \%, 13 / 18)$ as well as men with SCI $(60.0 \%, 15 / 25)$ compared with the reference groups of the same sex (women 13.5\%, 10/74 and men $13.0 \%, 6 / 46)$. However, the occurrence of osteopenia was higher in the reference groups (women $44.6 \%, 33 / 74$ and men $47.8 \%, 22 / 46)$ compared with women $(16.7 \%, 3 / 18)$ $(p=0.03)$ and men with SCI $(32.0 \%, 8 / 25)(p=0.2)$. There was no significant $(p=0.56)$ difference in the occurrence of osteoporosis and osteopenia between women with SCI and men with SCI.

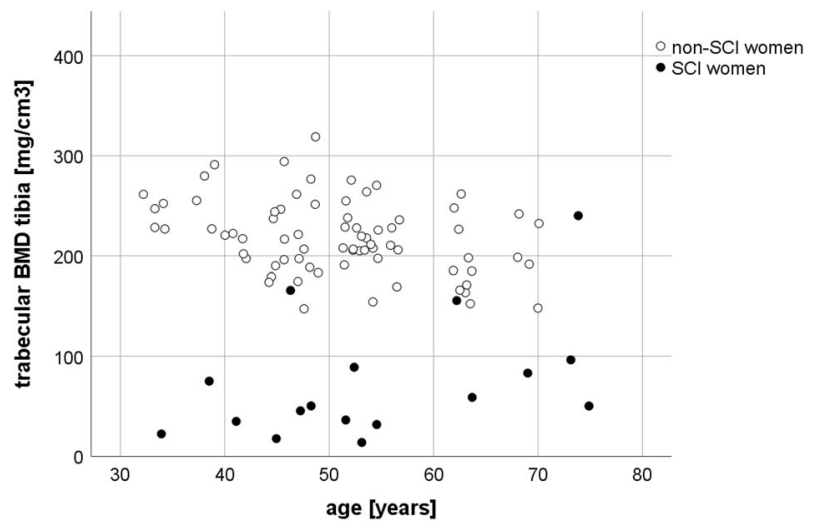

Fig. 1 Trabecular bone mineral density (BMD) of the tibial epiphysis in women with spinal cord injury and the reference group

\section{Fracture history and treatment}

The analysis of the long bone fracture history revealed that $49 \%(21 / 43)$ of the individuals with SCI and $21 \%$ $(25 / 120)$ of the reference individuals $(p=0.0004)$, respectively, had experienced 32 and 26 long bone fractures (or vertebral fracture in reference individuals), respectively, during the evaluation period (Table 3 ). In all groups, the majority of fractures was observed in the femur and the tibia (Table 3). The comparison of bone values between women and men with SCI who suffered fractures versus those who did not are presented in Table 4. Women with SCI who experienced fractures showed significantly $(p \leq 0.03)$ lower bone density values in all investigated locations, apart from the tibial epiphysis, compared with the women who did not. In men with SCI, those with fractures showed significantly $(p<$ $0.04)$ lower bone density values at all sites of measurement, apart from the femoral neck.

The fracture rates per 100 patient-years were 3.17 and 2.66 in women and men with SCI, respectively, compared with 0.85 and 0.21 in able-bodied women and men. The Kaplan-Meier analysis showed a significant $(p<0.001)$ difference in the time to the first fracture between women or men with SCI and their respective reference group, but no significant $(p=0.14)$ difference between women with SCI (22.3 years, 95\% CI 16.2-28.4 years) and men with SCI (27.3 years, 95\% CI 23.1-31.5 years) (Fig. 3). In contrast, there was a significant $(p=0.002)$ difference in the time to the first fracture between the sexes in the reference groups: earlier in women (31.3 years, 95\% CI 28.9-33.7 years) than in men $(42.0$ years, $95 \%$ CI 40.5-43.4 years).

Only $34 \%(6 / 18)$ and $32 \%(8 / 25)$ of the women and men with SCI, respectively, reported an intake of bone-active drugs or calcium and vitamin D. In women with a history of long bone fractures (9/18), one received a bisphosphonate 
Table 1 Bone parameters of women with spinal cord injury and women of the reference group

\begin{tabular}{|c|c|c|c|c|c|}
\hline & & $\begin{array}{l}\text { SCI women } \\
(n=18)\end{array}$ & $\begin{array}{l}\text { Reference women } \\
(n=74)\end{array}$ & Difference $^{\mathrm{a}}$ & $p^{\mathrm{b}}$ \\
\hline \multirow[t]{3}{*}{ Total hip } & aBMD $\left(\mathrm{g} / \mathrm{cm}^{2}\right)$ & $0.554 \pm 0.117$ & $0.89 \pm 0.12$ & $-38.4 \%$ & $<0.001$ \\
\hline & $\mathrm{BMC}(\mathrm{g})$ & $20.33 \pm 5.09$ & $30.991 \pm 5.719$ & $-35.0 \%$ & $<0.001$ \\
\hline & $Z$-score & $-2.63 \pm 0.78$ & $0.15 \pm 0.94$ & NA & $<0.001$ \\
\hline \multirow[t]{3}{*}{ Femoral neck } & aBMD $\left(\mathrm{g} / \mathrm{cm}^{2}\right)$ & $0.537 \pm 0.120$ & $0.774 \pm 0.119$ & $-31.4 \%$ & $<0.001$ \\
\hline & $\mathrm{BMC}(\mathrm{g})$ & $2.81 \pm 0.66$ & $3.85 \pm 0.65$ & $-27.5 \%$ & $<0.001$ \\
\hline & $Z$-score & $-2.02 \pm 1.01$ & $0.12 \pm 0.95$ & NA & $<0.001$ \\
\hline \multirow[t]{4}{*}{ Tibia $4 \%$} & $\begin{array}{l}\text { vBMDtrab } \\
\left(\mathrm{mg} / \mathrm{cm}^{3}\right)\end{array}$ & $74.6 \pm 61.1$ & $218.5 \pm 36.5$ & $-74.1 \%$ & $<0.001$ \\
\hline & vBMDtot $\left(\mathrm{mg} / \mathrm{cm}^{3}\right)$ & $126.9 \pm 48.9$ & $287.5 \pm 41.8$ & $-58.0 \%$ & $<0.001$ \\
\hline & $\mathrm{BMC}(\mathrm{g})$ & $1.41 \pm 0.58$ & $3.00 \pm 0.46$ & $-55.6 \%$ & $<0.001$ \\
\hline & CSAtot $\left(\mathrm{mm}^{2}\right)$ & $1108.5 \pm 100.6$ & $1050.8 \pm 125.3$ & $+5.8 \%$ & 0.013 \\
\hline \multirow[t]{4}{*}{ Tibia $38 \%$} & $\begin{array}{l}\text { vBMDcort } \\
\left(\mathrm{mg} / \mathrm{cm}^{3}\right)\end{array}$ & $1116.9 \pm 58.3$ & $1168.7 \pm 40.9$ & $-4.5 \%$ & $<0.001$ \\
\hline & $\mathrm{BMC}(\mathrm{g})$ & $2.59 \pm 0.56$ & $3.48 \pm 0.49$ & $-26.5 \%$ & $<0.001$ \\
\hline & CSAcort $\left(\mathrm{mm}^{2}\right)$ & $192.8 \pm 49.5$ & $268.3 \pm 36.5$ & $-29.7 \%$ & $<0.001$ \\
\hline & SSIpol $\left(\mathrm{mm}^{3}\right)$ & $1325 \pm 280$ & $1744 \pm 525$ & $-22.7 \%$ & $<0.001$ \\
\hline
\end{tabular}

Total hip and femoral neck values were measured by DXA. Tibial values were measured by pQCT. Values are presented as mean \pm standard deviation

SCI, spinal cord injury, tibia $4 \%$ tibial epiphysis, tibia $38 \%$ tibial diaphysis aBMD areal bone mineral density, $v B M D$ volumetric bone mineral density, $B M C$ bone mineral content, $v B M D$ trab volumetric trabecular bone mineral density, vBMDtot volumetric total bone mineral density, CSAtot total bone crosssectional area, vBMDcort volumetric cortical bone mineral density, CSAcort cortical bone cross-sectional area, SSIpol polar strength-strain index, NA geometric mean cannot be calculated due to negative values

${ }^{a}$ Relative difference between SCI and reference group = geometric mean value SCI group/geometric mean value reference group -1

${ }^{\mathrm{b}}$ Analysis of covariance (ANCOVA)

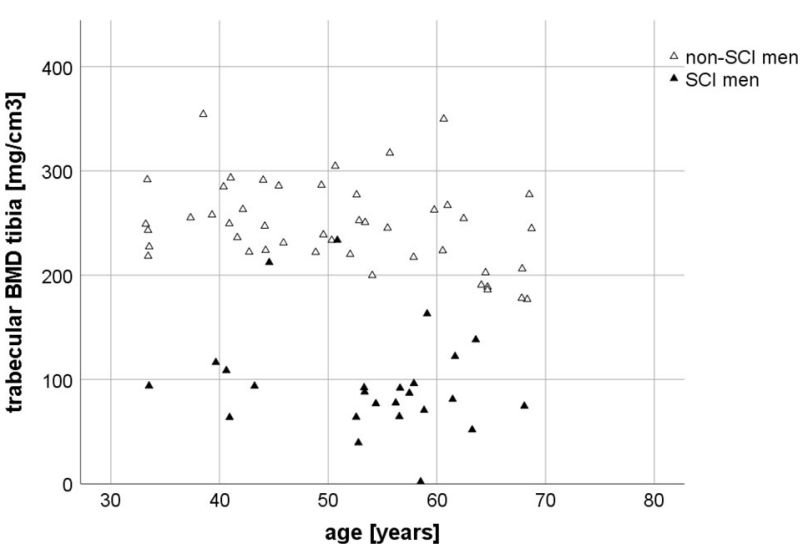

Fig. 2 Trabecular bone mineral density (BMD) of the tibial epiphysis in men with spinal cord injury and the reference group

and two calcium and vitamin D. In women without fractures (9/18), two reported an intake of calcium and vitamin D. In men with a history of long bone fracture (12/25), one took a bisphosphonate, and four calcium and vitamin D. In men without fractures (13/25), two took calcium and vitamin D and one just calcium.

\section{Discussion}

We have investigated the bone parameters and long bone fracture occurrence in women and men with chronic $(\geq 7$ years) motor complete SCI. BMD values at the femur (i.e., total hip, femoral neck) and tibia (i.e., distal epiphysis, diaphysis) were much lower in women and men with SCI compared with the respective able-bodied reference groups. The order of magnitude of this difference was similar in both women and men with SCI. Approximately one-half of the investigated individuals with SCI (women 50\%, men $48 \%$ ) had sustained a long bone fracture after the onset of SCI. The fracture occurrence was 3.17 and 2.66 fractures per 100 patient-years in women and men with SCI, respectively.

In women with long-term (mean 23 years after SCI), motor complete SCI, bone loss was most prominent in the distal tibia epiphysis $(-50$ to $-74 \%)$. This is in accordance with the observations of Eser et al. [6], who have reported a reduction of $73 \%, 58 \%$, and $57 \%$ in vBMDtrab, vBMDtot, and $\mathrm{BMC}$, respectively, at the distal tibia of men with motor complete SCI and a mean time since injury of 12 years. 
Table 2 Bone parameters of men with spinal cord injury and men of the reference group

\begin{tabular}{llcccc}
\hline & & SCI men $(n=25)$ & Reference men $(n=46)$ & Difference & $p^{\mathrm{b}}$ \\
\hline Total hip & aBMD $\left(\mathrm{g} / \mathrm{cm}^{2}\right)$ & $0.653 \pm 0.145$ & $0.974 \pm 0.140$ & $-33.9 \%$ & $<0.001$ \\
& BMC $(\mathrm{g})$ & $29.65 \pm 7.91$ & $43.11 \pm 8.25$ & $-32.4 \%$ & $<0.001$ \\
& Z-score & $-2.12 \pm 1.00$ & $-0.06 \pm 0.91$ & NA & $<0.001$ \\
Femoral neck & aBMD $\left(\mathrm{g} / \mathrm{cm}^{2}\right)$ & $0.606 \pm 0.133$ & $0.836 \pm 0.145$ & $-28.1 \%$ & $<0.001$ \\
& BMC $(\mathrm{g})$ & $3.50 \pm 0.91$ & $4.77 \pm 0.84$ & $-27.7 \%$ & $<0.001$ \\
& Z-score & $-1.56 \pm 1.09$ & $0.04 \pm 1.04$ & NA & $<0.001$ \\
Tibia 4\% & vBMDtrab $\left(\mathrm{mg} / \mathrm{cm}^{3}\right)$ & $96.1 \pm 49.7$ & $247.736 \pm 40.953$ & $-67.8 \%$ & $<0.001$ \\
& vBMDtot $\left(\mathrm{mg} / \mathrm{cm}^{3}\right)$ & $157.5 \pm 54.7$ & $324.858 \pm 48.233$ & $-53.6 \%$ & $<0.001$ \\
& BMC $(\mathrm{g})$ & $2.10 \pm 0.69$ & $4.09 \pm 0.76$ & $-50.4 \%$ & $<0.001$ \\
& CSAtot $\left(\mathrm{mm}^{2}\right)$ & $1353.6 \pm 224.6$ & $1262.45 \pm 163.27$ & $+6.7 \%$ & 0.021 \\
Tibia 38\% & vBMDcort $\left(\mathrm{mg} / \mathrm{cm}^{3}\right)$ & $1123.2 \pm 60.4$ & $1154.19 \pm 31.76$ & $-2.8 \%$ & 0.002 \\
& BMC $(\mathrm{g})$ & $3.40 \pm 0.74$ & $4.43 \pm 0.67$ & $-24.3 \%$ & $<0.001$ \\
& CSAcort $\left(\mathrm{mm}^{2}\right)$ & $258.6 \pm 63.3$ & $350.190 \pm 55.956$ & $-27.7 \%$ & $<0.001$ \\
& SSIpol $\left(\mathrm{mm}^{3}\right)$ & $1796 \pm 375$ & $2381 \pm 620$ & $-23.9 \%$ & $<0.001$ \\
\hline
\end{tabular}

Total hip and femoral neck values were measured by DXA. Tibial values were measured by pQCT. Values are presented as mean \pm standard deviation

SCI spinal cord injury, tibia $4 \%$ tibial epiphysis, tibia $38 \%$ tibial diaphysis, aBMD areal bone mineral density, $v B M D$ volumetric bone mineral density, $B M C$ bone mineral content, $v B M D$ trab volumetric trabecular bone mineral density, vBMDtot total volumetric bone mineral density, CSAtot total bone crosssectional area, vBMDcort volumetric cortical bone mineral density, CSAcort cortical bone cross-sectional area, SSIpol polar strength-strain index, $N A$ geometric mean cannot be calculated due to negative values

${ }^{a}$ Relative difference between SCI and reference group = geometric mean value SCI group / geometric mean value reference group -1

${ }^{\mathrm{b}}$ Analysis of covariance (ANCOVA)

\begin{tabular}{lllll}
\hline & Reference women & SCI women & SCI men & Reference men \\
\hline Fracture rate & $24.3 \%(18 / 74)$ & $50.0 \%(9 / 18)$ & $48.0 \%(12 / 25)$ & $15.2 \%(7 / 46)$ \\
Fracture ratio & $1.06(19 / 18)$ & $1.44(13 / 9)$ & $1.58(19 / 12)$ & $1.0(7 / 7)$ \\
Humerus & $10.5 \%(2 / 19)$ & No fractures & $5.3 \%(1 / 19)$ & $28.6 \%(2 / 7)$ \\
Radius & No fractures & No fractures & No fractures & No fractures \\
Spine & $36.8 \%(7 / 19)$ & No fractures & No fractures & No fractures \\
Femur & $10.5 \%(2 / 19)$ & $46.2 \%(6 / 13)$ & $57.9 \%(11 / 19)$ & No fractures \\
Tibia & $52.6 \%(10 / 19)$ & $53.8 \%(7 / 13)$ & $36.8 \%(7 / 19)$ & $71.4 \%(5 / 7)$ \\
\hline
\end{tabular}

SCI spinal cord injury. fracture rate proportion of individuals with fractures, fracture ratio fractures/ individuals with fractures
Table 3 Fractures in the investigated groups
Data regarding bone values in women after SCI are very sparse. Garland et al. $[12,14]$ have reported total hip (0.39$\left.0.65 \mathrm{~g} / \mathrm{cm}^{2}\right)$ and knee aBMD $\left(0.45-0.58 \mathrm{~g} / \mathrm{cm}^{2}\right)$ in women with chronic (mean duration of injury $\geq 6$ years), complete SCI. These values are comparable with our results.

In our study, the total hip and femoral neck $Z$-scores were not significantly lower in women compared with men. The effect of SCI on bone metabolism seems to be greater than the effect of sex. Coupaud et al. [15] have investigated the changes in bone quality from injury until 12 months after SCI and have observed a tendency for a greater decrease in vBMD in women. However, the differences did 
Table 4 Bone parameters of women and men after spinal cord injury with and without fractures

\begin{tabular}{|c|c|c|c|c|c|c|c|}
\hline & & $\begin{array}{l}\text { SCI women with } \mathrm{fx} \\
(n=9)\end{array}$ & $\begin{array}{l}\text { SCI women without } \mathrm{fx} \\
(n=9)\end{array}$ & $p^{\mathrm{a}}$ & $\begin{array}{l}\text { SCI men with } f x \\
(n=12)\end{array}$ & $\begin{array}{l}\text { SCI men without } \mathrm{fx} \\
(n=13)\end{array}$ & $p^{\mathrm{b}}$ \\
\hline \multirow[t]{3}{*}{ Total hip } & $\operatorname{aBMD}\left(\mathrm{g} / \mathrm{cm}^{2}\right)$ & $0.420 \pm 0.082$ & $0.634 \pm 0.100$ & 0.004 & $0.577 \pm 0.126$ & $0.718 \pm 0.132$ & 0.014 \\
\hline & $\mathrm{BMC}(\mathrm{g})$ & $16.854 \pm 2.634$ & $24.239 \pm 4.274$ & 0.001 & $25.633 \pm 6.200$ & $33.049 \pm 7.789$ & 0.018 \\
\hline & $Z$-score & $-2.96 \pm 0.69$ & $-1.91 \pm 0.80$ & 0.03 & $-2.65 \pm 0.83$ & $-1.73 \pm 0.87$ & 0.016 \\
\hline \multirow[t]{3}{*}{ Femoral neck } & $\mathrm{aBMD}\left(\mathrm{g} / \mathrm{cm}^{2}\right)$ & $0.473 \pm 0.068$ & $0.609 \pm 0.129$ & 0.15 & $0.554 \pm 0.116$ & $0.650 \pm 0.135$ & 0.08 \\
\hline & $\mathrm{BMC}(\mathrm{g})$ & $2.437 \pm 0.241$ & $3.238 \pm 0.729$ & 0.007 & $3.233 \pm 0.862$ & $3.728 \pm 0.926$ & 0.2 \\
\hline & $Z$-score & $-2.34 \pm 0.86$ & $-1.31 \pm 0.91$ & 0.03 & $-1.96 \pm 0.93$ & $-1.25 \pm 1.01$ & 0.09 \\
\hline \multirow[t]{4}{*}{ Tibia $4 \%$} & $\begin{array}{l}\text { vBMDtrab } \\
\left(\mathrm{mg} / \mathrm{cm}^{3}\right)\end{array}$ & $52.5 \pm 47.3$ & $94.1 \pm 67.8$ & 0.2 & $76.7 \pm 42.5$ & $114.0 \pm 50.6$ & 0.059 \\
\hline & vBMDtot $\left(\mathrm{mg} / \mathrm{cm}^{3}\right)$ & $110.8 \pm 43.3$ & $141.3 \pm 51.4$ & 0.2 & $132.5 \pm 35.0$ & $180.5 \pm 60.5$ & 0.025 \\
\hline & $\mathrm{BMC}(\mathrm{g})$ & $1.22 \pm 0.50$ & $1.58 \pm 0.62$ & 0.2 & $1.80 \pm 0.59$ & $2.37 \pm 0.69$ & 0.039 \\
\hline & CSAtot $\left(\mathrm{mm}^{2}\right)$ & $1104.0 \pm 96.6$ & $1112.5 \pm 109.8$ & 0.9 & $1359.8 \pm 213.1$ & $1347.8 \pm 243.2$ & 0.9 \\
\hline \multirow[t]{4}{*}{ Tibia $38 \%$} & $\begin{array}{l}\text { vBMDcort } \\
\left(\mathrm{mg} / \mathrm{cm}^{3}\right)\end{array}$ & $1102.1 \pm 44.6$ & $1130.0 \pm 68.2$ & 0.3 & $1090.7 \pm 60.6$ & $1153.2 \pm 43.4$ & 0.007 \\
\hline & $\mathrm{BMC}(\mathrm{g})$ & $2.23 \pm 0.35$ & $2.91 \pm 0.51$ & 0.006 & $3.02 \pm 0.68$ & $3.76 \pm 0.63$ & 0.009 \\
\hline & CSAcort $\left(\mathrm{mm}^{2}\right)$ & $161.2 \pm 28.5$ & $220.8 \pm 48.0$ & 0.008 & $226.0 \pm 57.8$ & $288.8 \pm 53.9$ & 0.01 \\
\hline & SSIpol $\left(\mathrm{mm}^{3}\right)$ & $1163 \pm 197$ & $1469 \pm 270$ & 0.019 & $1624 \pm 375$ & $1954 \pm 309$ & 0.025 \\
\hline
\end{tabular}

Total hip and femoral neck values were measured by DXA. Tibial values were measured by pQCT. Values are presented as mean \pm standard deviation

$S C I$ spinal cord injury, $f x$ fracture(s), tibia $4 \%$ tibial epiphysis, tibia $38 \%$ tibial diaphysis, $a B M D$ areal bone mineral density, $v B M D$ volumetric bone mineral density, $B M C$ bone mineral content, $v B M D$ trab volumetric trabecular bone mineral density, $v B M D t o t$ volumetric total bone mineral density, CSAtot total bone cross-sectional area, $v B M D$ cort volumetric cortical bone mineral density, CSAcort cortical bone cross-sectional area, SSIpol polar strength-strain index

${ }^{\mathrm{a}} p$-value for difference between women with fractures and those without fractures

${ }^{\mathrm{b}} p$-value for difference between men with fractures and those without fractures

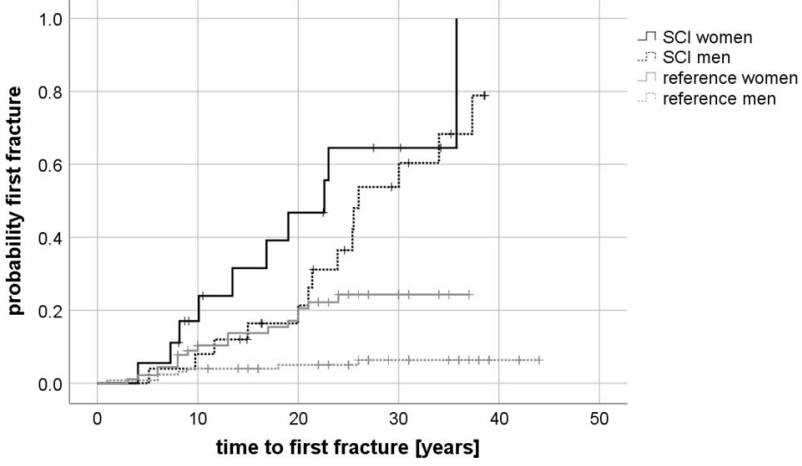

Fig. 3 The Kaplan-Meier one-minus-survival plot showing the cumulative probability estimates for the occurrence of the first fracture. SCI spinal cord injury. + : censored

not reach statistical significance. In contrast, Garland et al. [12] have reported significantly lower aBMD values in women with SCI compared with men with SCI. Unfortunately, the number of women in menopause in our cohort was too small $(n=10)$ to investigate the effect of menopause on bone loss in SCI women. However, the effect of SCI on bone quality seems to be greater than that of estrogen loss [16].
The characteristic deterioration of bone quality below the level of injury in individuals with motor complete SCI results, at least in part, from the absence of weight-bearing activities [17]. Other factors seem to be involved too. Sympathetic nerves appear to have an effect on bone metabolism, and altered sympathetic activity may therefore contribute to bone loss after SCI [18]. Furthermore, hormonal changes following SCI (e.g., decreased sex steroid levels, vitamin D deficiency, calcium imbalance) and systemic as well as local inflammatory mediators may exacerbate bone loss [19].

The important loss of bone quantity and quality in women and men with SCI is associated with an increased risk of lower limb fractures, primarily at the femur and the tibia, where bone loss is most prominent [20-22]. Fractures occur when the mechanical forces exceed the capacity of bone to preserve integrity [23]. In the present study, $56 \%$ of the fractures affected the femur and $41 \%$ the tibia. The previously reported percentages range from 20 to $61 \%$ for the femur and from 20 to $63 \%$ for the tibia [9, 20-22, 24]. Fractures of the femur and tibia in individuals with SCI are most commonly the result of low-impact injuries when falling out of a wheelchair or falling during a transfer $[9,20,22]$. Nearly half of the individuals with SCI in our 
study were affected by long bone fractures. Previously reported fracture occurrence rates in individuals with SCI are lower (i.e., 10-34\%) compared with our data [22, 24], which may result from differences in the evaluated cohorts and the calculation of fracture rates. In the present study, the fracture rate was 3.17 and 2.66 fractures per 100 patientyears in women and men with SCI, which is consistent with those reported in earlier studies (2.9-3.9 fractures per 100 patient-years) $[8,22]$. Our findings did not reveal any significant difference between sexes regarding fracture rates in individuals with SCI. This is in contrast to the situation in the non-SCI population, where women have a greater lifetime fracture risk compared with men, because of differences in bone metabolism, BMD, bone architecture, size, and strength $[25,26]$.

In the SCI population, preventing and managing bone loss in order to reduce the occurrence of fractures is therefore of great clinical importance in both women and men. Long bone fractures and associated complications represent a considerable burden for the affected individuals [9, 10, 21, 22], with complications occurring in $50 \%$ of them [ 9,22$]$. Such typical fracture complications include non-union, delayed healing, and pressure ulcers [9, 21]. Carbone et al. [10] documented a significant association between the occurrence of lower extremity fractures and increased mortality (hazard ratio 3.13 ) in older men ( $>50$ years old) with chronic traumatic SCI ( $\geq 2$ years after injury). In our study, only $33 \%$ of the investigated women and men reported to take bone-active drugs, including calcium and vitamin $\mathrm{D}$, which is in accordance with previous reports (i.e., 20-33\%) [9, 20, 22]. This may be due to unawareness concerning bone loss in individuals with SCI or the lack of recommendations regarding the optimal anti-resorptive and/or bone stimulating therapy in these individuals. Future efforts need being directed towards developing evidence-based therapeutic schemes to prevent and treat bone loss in individuals with SCI. Furthermore, strategies to prevent falls out of the wheelchair and during transfer should be developed.

In conclusion, both women and men with chronic motor complete SCI show markedly reduced bone densitometry values in the proximal femur, tibial diaphysis and distal tibial epiphysis. One in two individuals with SCI is expected to sustain at least one long bone fracture during a lifetime. Preventative and therapeutic strategies against bone loss should be developed for women and men with SCI.

\section{Data archiving}

The data analyzed during the current study are available from the corresponding author on reasonable request.
Acknowledgements The authors thank Dr Dirk Lehnick for his assistance with the statistical analyses.

Author contributions AF: conception and design, acquisition of data, analysis and interpretation of data, drafting of the manuscript, and approval of final version. JK: analysis and interpretation of data, drafting of the manuscript, approval of final version. AG: analysis and interpretation of data, drafting of the manuscript, approval of final version. $\mathrm{KH}$ : acquisition of data, revised the manuscript for important intellectual content, and approval of final version. ST: analysis and interpretation of data, revised the manuscript for important intellectual content, and approval of final version. KL: conception and design, supervision, analysis and interpretation of data, revised the manuscript for important intellectual content, and approval of final version

\section{Compliance with ethical standards}

Ethical statement This study had been approved by the Ethics Committee of Northwestern and Central Switzerland. All participants provided written informed consent before participation in the study. We certify that all applicable institutional and governmental regulations concerning the ethical use of human volunteers were followed during the course of this research.

Conflict of interest The authors declare that they have no conflict of interest.

Publisher's note Springer Nature remains neutral with regard to jurisdictional claims in published maps and institutional affiliations.

\section{References}

1. Biering-Sorensen F, Bohr HH, Schaadt OP. Longitudinal study of bone mineral content in the lumbar spine, the forearm and the lower extremities after spinal cord injury. Eur J Clin Investig. 1990;20:330-5.

2. Garland DE, Adkins RH. Bone loss at the knee in spinal cord injury. Top Spinal Cord Inj Rehabil. 2001;6:37-46.

3. de Bruin ED, Vanwanseele B, Dambacher MA, Dietz V, Stussi E. Long-term changes in the tibia and radius bone mineral density following spinal cord injury. Spinal Cord. 2005;43:96-101.

4. Edwards WB, Schnitzer TJ, Troy KL. Bone mineral loss at the proximal femur in acute spinal cord injury. Osteoporos Int. 2013;24:2461-9.

5. Edwards WB, Schnitzer TJ, Troy KL. Reduction in proximal femoral strength in patients with acute spinal cord injury. J Bone Min Res. 2014;29:2074-9.

6. Eser P, Frotzler A, Zehnder Y, Wick L, Knecht H, Denoth J, et al. Relationship between the duration of paralysis and bone structure: a pQCT study of spinal cord injured individuals. Bone. 2004;34:869-80.

7. Frotzler A, Berger M, Knecht H, Eser P. Bone steady-state is established at reduced bone strength after spinal cord injury: a longitudinal study using peripheral quantitative computed tomography (pQCT). Bone. 2008;43:549-55.

8. Zehnder Y, Luthi M, Michel D, Knecht H, Perrelet R, Neto I, et al. Long-term changes in bone metabolism, bone mineral density, quantitative ultrasound parameters, and fracture incidence after spinal cord injury: a cross-sectional observational study in 100 paraplegic men. Osteoporos Int. 2004;15:180-9. 
9. Morse LR, Battaglino RA, Stolzmann KL, Hallett LD, Waddimba A, Gagnon D, et al. Osteoporotic fractures and hospitalization risk in chronic spinal cord injury. Osteoporos Int. 2009;20:385-92.

10. Carbone LD, Chin AS, Burns SP, Svircev JN, Hoenig H, Heggeness $\mathrm{M}$, et al. Mortality after lower extremity fractures in men with spinal cord injury. J Bone Min Res. 2014;29:432-9.

11. Coupaud S, McLean AN, Purcell M, Fraser MH, Allan DB. Decreases in bone mineral density at cortical and trabecular sites in the tibia and femur during the first year of spinal cord injury. Bone. 2015;74:69-75.

12. Garland DE, Adkins RH, Stewart CA. Five-year longitudinal bone evaluations in individuals with chronic complete spinal cord injury. J Spinal Cord Med. 2008;31:543-50.

13. McCarthy ID, Bloomer Z, Gall A, Keen R, Ferguson-Pell M. Changes in the structural and material properties of the tibia in patients with spinal cord injury. Spinal Cord. 2012;50:333-7.

14. Garland DE, Adkins RH, Stewart CA, Ashford R, Vigil D. Regional osteoporosis in women who have a complete spinal cord injury. J Bone Jt Surg Am. 2001;83-A:1195-200.

15. Coupaud S, McLean AN, Allan DB. Role of peripheral quantitative computed tomography in identifying disuse osteoporosis in paraplegia. Skelet Radio. 2009;38:989-95.

16. Slade JM, Bickel CS, Modlesky CM, Majumdar S, Dudley GA. Trabecular bone is more deteriorated in spinal cord injured versus estrogen-free postmenopausal women. Osteoporos Int. 2005;16:263-72.

17. Amin S. Mechanical factors and bone health: effects of weightlessness and neurologic injury. Curr Rheumatol Rep. 2010;12:170-6.
18. He JY, Jiang LS, Dai LY. The roles of the sympathetic nervous system in osteoporotic diseases: a review of experimental and clinical studies. Ageing Res Rev. 2011;10:253-63.

19. Jiang SD, Jiang LS, Dai LY. Mechanisms of osteoporosis in spinal cord injury. Clin Endocrinol. 2006;65:555-65.

20. Akhigbe T, Chin AS, Svircev JN, Hoenig H, Burns SP, Weaver FM, et al. A retrospective review of lower extremity fracture care in patients with spinal cord injury. J Spinal Cord Med. 2015;38:2-9.

21. Frotzler A, Cheikh-Sarraf B, Pourtehrani M, Krebs J, Lippuner K. Long-bone fractures in persons with spinal cord injury. Spinal Cord. 2015;53:701-4.

22. Gifre L, Vidal J, Carrasco J, Portell E, Puig J, Monegal A, et al. Incidence of skeletal fractures after traumatic spinal cord injury: a 10-year follow-up study. Clin Rehabil. 2014;28:361-9.

23. Jarvinen TL, Michaelsson K, Aspenberg P, Sievanen H. Osteoporosis: the emperor has no clothes. J Intern Med. 2015;277:662-73.

24. Lazo MG, Shirazi P, Sam M, Giobbie-Hurder A, Blacconiere MJ, Muppidi M. Osteoporosis and risk of fracture in men with spinal cord injury. Spinal Cord. 2001;39:208-14.

25. Riggs BL, Melton Iii LJ 3rd, Robb RA, Camp JJ, Atkinson EJ, Peterson JM, et al. Population-based study of age and sex differences in bone volumetric density, size, geometry, and structure at different skeletal sites. J Bone Min Res. 2004;19:1945-54.

26. Nicks KM, Amin S, Atkinson EJ, Riggs BL, Melton LJ 3rd, Khosla S. Relationship of age to bone microstructure independent of areal bone mineral density. J Bone Min Res. 2012;27:637-44. 